\title{
Building the Airplane While Flying It: The Story of Ongoing Efforts to Establish and Evaluate a Multidisciplinary Team Response to VE in Massachusetts US +
}

\section{B. Heidi Ellis}

Citation: Ellis, B.H. Building the Airplane While Flying It: The Story of Ongoing Efforts to Establish and Evaluate a Multidisciplinary Team Response to VE in Massachusetts US. Proceedings 2021, 77, 10. https://doi.org/10.3390/proceedings2021077010

Published: 26 April 2021

Publisher's Note: MDPI stays neutral with regard to jurisdictional claims in published maps and institutional affiliations.

Copyright: $\odot 2021$ by the authors. Licensee MDPI, Basel, Switzerland. This article is an open access article distributed under the terms and conditions of the Creative Commons Attribution (CC BY) license (http://creativecommons.org/licenses/by/4.0/).
Department of Psychiatry, Boston Children's Hospital, Boston, MA 02115, USA;

Heidi.ellis@childrens.harvard.edu

† Presented at the Global Safety Evaluation Workshop, Online, 1 July-31 December 2020.

\begin{abstract}
Research on mental health and violence among marginalized communities has identified the importance of engaging communities, diminishing stigma, addressing multiple outcomes including strengths, and building social connections. Within the United States, Countering Violent Extremism (CVE) policies and programs have been criticized for failing in these areas. Recent efforts have sought to build multidisciplinary teams for the prevention of targeted violence and terrorism that explicitly seek to address these critiques and work to build the capacity of multidisciplinary providers to work with youth at risk for targeted violence and terrorism. Community Connect was a Boston, US-based community-based program that worked with youth at risk of violence, including ideologically-based violence. This program achieved broad community buy-in and successfully linked referred youth to a broad range of services in their communities. To bring the program to scale, an adaptation of Community Connect was developed that accepted referrals from a regional federally-convened threat assessment team, the Massachusetts Bay Threat Assessment Team (MassBayTAT). This multidisciplinary services team (MDST) maintains several essential functions from Community Connect, such as providing a thorough psychosocial assessment and maintaining regular contact and coordination between diverse providers, as well as making key changes to accommodate a regional scope. Given the nascent state of the field, both formative as well as summative evaluations play important roles in shaping and evaluating multidisciplinary violence prevention teams, as is evident in the iterative adaptation of the above-described multidisciplinary approaches. Evaluation of a multidisciplinary team for VE should assess both team development as well as case outcomes. Building trust within a community of diverse providers and disciplines and achieving a 'whole of society' approach to violence prevention is in and of itself an outcome that should be sought, as well as a reduction in violence at the individual level. Mixed-methods evaluations are needed to capture both the process and outcomes that are central to an effective multidisciplinary team for the prevention of terrorism and targeted violence.
\end{abstract}

Keywords: counterterrorism; countering violent extremism; multidisciplinary; formative evaluation 